\title{
Assessing the Role of the Cadherin/Catenin Complex at the Schwann Cell-Axon Interface and in the Initiation of Myelination
}

\author{
Kathryn A. Lewallen, ${ }^{1}$ Yun-An A. Shen, ${ }^{2}$ Asia R. De La Torre, ${ }^{1}$ Benjamin K. Ng, ${ }^{1}$ Dies Meijer, ${ }^{3}$ and Jonah R. Chan ${ }^{1,2}$ \\ ${ }^{1}$ Department of Biochemistry and Molecular Biology, Zilkha Neurogenetic Institute, Keck School of Medicine, University of Southern California, Los \\ Angeles, California 90033, ${ }^{2}$ Department of Neurology and Program in Neuroscience, University of California, San Francisco, San Francisco, California \\ 94158, and ${ }^{3}$ Department of Cell Biology and Genetics, Erasmus University Medical Center, 3015 GE Rotterdam, The Netherlands
}

Myelination is dependent on complex reciprocal interactions between the Schwann cell (SC) and axon. Recent evidence suggests that the SC-axon interface represents a membrane specialization essential for myelination; however, the manner in which this polarized-apical domain is generated remains a mystery. The cell adhesion molecule N-cadherin is enriched at the SC-axon interface and colocalizes with the polarity protein Par-3. The asymmetric localization is induced on SC-SC and SC-axon contact. Knockdown of N-cadherin in SCs cocultured with DRG neurons disrupts Par-3 localization and delays the initiation of myelination. However, knockdown or overexpression of neuronal $\mathrm{N}$-cadherin does not influence the distribution of Par-3 or myelination, suggesting that homotypic interactions between SC and axonal N-cadherin are not essential for the events surrounding myelination. To further investigate the role of N-cadherin, mice displaying SC-specific gene ablation of N-cadherin were generated and characterized. Surprisingly, myelination is only slightly delayed, and mice are viable without any detectable myelination defects. $\beta$-Catenin, a downstream effector of $\mathrm{N}$-cadherin, colocalizes and coimmunoprecipitates with $\mathrm{N}$-cadherin on the initiation of myelination. To determine whether $\beta$-catenin mediates compensation on $\mathrm{N}$-cadherin deletion, SC-specific gene ablation of $\beta$-catenin was generated and characterized. Consistent with our hypothesis, myelination is more severely delayed than when manipulating $\mathrm{N}$-cadherin alone, but without any defect to the myelin sheath. Together, our results suggest that $\mathrm{N}$-cadherin interacts with $\beta$-catenin in establishing SC polarity and the timely initiation of myelination, but they are nonessential components for the formation and maturation of the myelin sheath.

\section{Introduction}

The generation of cell polarity is critical for development, serving to organize and integrate complex molecular signals in order for cells to function properly and make decisions concerning fate and differentiation. In the nervous system, the initiation of myelination requires the coordination and integration of multiple signals that result in dynamic morphological changes and the subsequent unidirectional wrapping of multiple layers of membrane concentrically around an axon. Ensheathment and wrapping are initiated at the site of the Schwann cell (SC)-axon interface and require specific molecular cues for axonal recognition, adhesion, and induction of this process (Nave and Salzer, 2006; Chan, 2007). Although myelination is unquestionably a highly polar-

\footnotetext{
Received Aug. 18, 2010; revised 0ct. 18, 2010; accepted Nov. 24, 2010.

This work was supported by National Institutes of Health-National Institute of Neurological Disorders and Stroke Grant NS062796-03, The Donald E. and Delia B. Baxter Foundation Award 92-5104-1190, and National Multiple Sclerosis Society Career Transition Award TA 3008A1/1T (J.R.C.). We acknowledge Prof. Masatoshi Takeichi for generously providing the full-length $\mathrm{N}$-cadherin cDNA. We also thank the members of the Chan Laboratory for their encouragement, discussions, and scientific insight, as well as Drs. Ralf Langen and Yujin Kim for assistance with the electron microscopy.

Correspondence should be addressed to Dr. Jonah R. Chan, Department of Neurology and Program in Neuroscience, University of California, San Francisco, 600 16th Street, S576, Box 2280, San Francisco, CA 94143. E-mail: jonah.chan@ucsf.edu.

DOI:10.1523/JNEUROSCI.4345-10.2011

Copyright $\odot 2011$ the authors $\quad 0270-6474 / 11 / 313032-12 \$ 15.00 / 0$
}

ized process, the mechanisms involved in the generation of SC polarity remain mostly uncharacterized.

The partitioning defective (Par) proteins represent a family of molecules involved in establishing cell polarity, mediating cellular asymmetry through the formation of a molecular complex (Munro, 2006; Goldstein and Macara, 2007). Par-3 is asymmetrically localized to the SC-axon interface and this localization is dependent on SC-axon contact. Disruption of the localization of Par-3 inhibits myelination, without affecting cell division, migration, or axonal alignment (Chan et al., 2006). This finding represents a unique membrane specialization in the SC that may be responsible for the recruitment of signaling molecules and receptors to the SC-axon interface that leads to the unidirectional wrapping of the SC membrane. Although much has been learned concerning the establishment and stabilization of cell polarity, relatively little is known about the extrinsic cues that initiate asymmetry.

In mammalian epithelial cells, intercellular contact and focal adhesions recruit the Par complex to the apical and lateral domains of the cell (Perez-Moreno et al., 2003). These focal adhesions are formed by homotypic interactions of cadherin molecules. $\mathrm{N}$-cadherin is expressed on both SCs and neurons alike and is necessary throughout SC development. It plays important roles in proliferation, in migration, and in early SC precursor-axon interactions (Wanner and Wood, 2002; Wanner et 
al., 2006; Gess et al., 2008). We set out to characterize and manipulate the expression and localization of $\mathrm{N}$-cadherin in both SCs and DRG neurons in an in vitro coculture system, and find that $\mathrm{N}$-cadherin, $\beta$-catenin, and Par- 3 colocalize at the SC-axon interface and that asymmetric localization is induced on contact. Knockdown of N-cadherin in SCs disrupts Par-3 localization and delays the initiation of myelination. However, knockdown of neuronal $\mathrm{N}$-cadherin does not alter the redistribution of Par-3 in SCs nor does it elicit any observable effects on the initiation of myelination, inconsistent with the hypothesis that homotypic interactions between SC and neuronal N-cadherin initiate polarity and myelination. We report that myelination in mice displaying SC-specific ablation of $\mathrm{N}$-cadherin is only slightly delayed. To determine whether $\beta$-catenin could be responsible for a compensatory mechanism in the $\mathrm{N}$-cadherin deletion, SC-specific ablation of $\beta$-catenin was generated and characterized both in vitro and in vivo. Myelination was more severely delayed; however, the mice were without any detectable myelination defects. Together, we conclude that, although the cell adhesion molecule $\mathrm{N}$-cadherin may contribute to focal adhesion and establishing SC polarity, it is a nonessential molecular component in the initiation and maturation of the myelin sheath. Additional investigation and identification of adhesion molecules that share similar functions to N-cadherin in SCaxon interactions will provide insight into the compensatory mechanisms behind these findings.

\section{Materials and Methods}

Primary SC and DRG coculture. Purified DRG and SC cultures were established using methods described previously (Chan et al., 2006). Before isolating DRG neurons, tissue culture-treated plastic or glass coverslips were coated with rat tail collagen $2-3 \mathrm{~d}$ before dissection. DRGs are individually removed from rat embryos [embryonic day 15 (E15)] under sterile conditions and placed in a $15 \mathrm{ml}$ conical centrifuge tube with $5 \mathrm{ml}$ of L15 medium plus 10\% heat-inactivated FBS and allowed to settle. The DRGs were washed with $10 \mathrm{ml}$ of L15 medium without serum and then replaced with $5 \mathrm{ml}$ of $0.25 \%$ trypsin. The DRGs were incubated at $37^{\circ} \mathrm{C}$ for $45 \mathrm{~min}$. Trypsin was removed and DRGs were washed with $10 \mathrm{ml}$ of L15 plus 10\% FBS. The DRGs were allowed to settle or were centrifuged gently at $250 \times g$ for $10 \mathrm{~min}$. The medium was removed and replaced with 4-5 ml of DRG medium (high-glucose MEM, $10 \%$ heat-inactivated

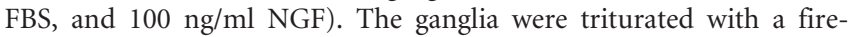
polished Pasteur pipette until the suspension was homogeneous and the dissociated DRGs were plated onto collagen-coated tissue culturetreated plastic or glass coverslips at a density of $\sim 150,000$ total cells per $25 \mathrm{~mm}$ coverslip at a volume of $400 \mu \mathrm{l}$. The next day, the wells were flooded with $1 \mathrm{ml}$ of medium containing antimitotic [high-glucose MEM, N2 supplement, $100 \mathrm{ng} / \mathrm{ml} \mathrm{NGF,} \mathrm{and} \mathrm{FdU} \mathrm{(fluorodeoxyuridine)].}$ After $2 \mathrm{~d}$, the medium was replaced with $1 \mathrm{ml}$ of the DRG medium. This feeding cycle was maintained by feeding cells with DRG medium or antimitotic medium alternately every $2 \mathrm{~d}$ for three complete cycles. The purified DRG neurons were cultured for an additional week before adding purified SCs.

SCs were purified from sciatic nerves from 2-d-old rat pups. Nerves were placed in L15 plus 10\% heat-inactivated FBS and allowed to settle. Sciatic nerves were washed twice with $\mathrm{L} 15$ and incubated at $37^{\circ} \mathrm{C}$ for 15 $\min$ in $3 \mathrm{ml}$ of a sterile $3 \mathrm{mg} / \mathrm{ml}$ collagenase solution. The collagenase was removed and replaced with a solution containing $3 \mathrm{ml}$ of fresh collagenase and $500 \mu \mathrm{l}$ of $0.25 \%$ trypsin. The nerves were then incubated at $37^{\circ} \mathrm{C}$ for $15 \mathrm{~min}$. The collagenase/trypsin solution was removed and the nerves were gently washed in $10 \mathrm{ml}$ of L15 plus FBS. The nerves were resuspended in a solution with $5 \mathrm{ml}$ of fresh L15 plus FBS and triturated with a fire-polished Pasteur pipette until thoroughly teased. The suspension was filtered through a $40 \mu \mathrm{m}$ nylon cell strainer. The strainer was rinsed with $5 \mathrm{ml}$ of L15 plus FBS. The suspension was centrifuged at $1500 \mathrm{rpm}$ for $15 \mathrm{~min}$, and cells were resuspended in $5 \mathrm{ml}$ of SC medium (DMEM, $10 \% \mathrm{FBS}$, and penn/strep). The suspension was plated into two $10 \mathrm{~cm}$ tissue culture dishes and the volume was brought up to $10 \mathrm{ml}$ per dish. The cells were incubated at $37^{\circ} \mathrm{C}$ overnight. The next day, the antimitotic AraC (cytosine arabinoside) was directly added to the culture dishes. Schwann cells were cultured for $\sim 3-4 \mathrm{~d}$ and the medium was replaced with fresh medium without antimitotic. The SC medium was replaced every third day and the cells were typically cultured for an additional week before plating onto DRG neurons. Approximately 100,000 SCs were seeded onto purified neuronal cultures and allowed to proliferate and ensheath the axons ( $\sim 1$ week). Myelination was then initiated with the addition of ascorbic acid $(50 \mu \mathrm{g} / \mathrm{ml})$, which allows for the formation of the basal lamina, an essential component for SC myelination.

Short hairpin RNA and retroviral/lentiviral vectors. N-cadherin and control short hairpin RNA (shRNA) sequences were obtained through Clontech small interfering RNA hairpin oligo sequence designer. N-cadherin shRNA (corresponding to position 97) was as follows: 5'-GACTGGATTTCCTGAAGAT-3'. N-cadherin control shRNA (corresponding to position 1618) was as follows: $5^{\prime}$-CTGCCAACTGGCTGAAAAT- $3^{\prime}$. The N-cadherin shRNA sequences were obtained from previous studies for N-cadherin knockdown (Maeda et al., 2005; Ezzat et al., 2006). The N-cadherin control and shRNA sequences were ligated directly into the pSIREN-RetroR-ZsGreen retroviral plasmid (Clontech). Retroviral production was achieved by transfecting Phoenix cells as previously described (Grignani et al., 1998; Chan et al., 2006). SC-DRG cocultures were infected with retrovirus during the proliferation stage of the $\mathrm{SC}(\sim 5 \mathrm{~d}$ after seeding onto DRG neurons) to increase infection efficiency. Retroviral vectors were prepared and purified as previously described (Cayouette and Raff, 2003). The retroviral supernatants were prepared in MEM medium containing $10 \%$ FBS and NGF and added to cocultures for $48-72 \mathrm{~h}$. Additionally, the $\mathrm{N}$-cadherin control and shRNA sequences were ligated directly into the pLentiLox 3.7 lentiviral plasmid. Lentiviral production was achieved by transfecting 293FT cells with plasmid DNA and viral packaging components according to the manufacturer's instructions (Clontech). Supernatant was harvested $48-72 \mathrm{~h}$ after transfection and centrifuged to remove cellular debris. DRG neurons were infected for $48 \mathrm{~h}$ and then maintained in MEM medium containing $10 \%$ FBS and NGF for $\sim 2$ weeks to allow sufficient time for expression, as indicated by green fluorescent protein (GFP) in axonal processes, and to eliminate the risk of infecting SCs.

$N$-cadherin overexpression and nucleofection. The full-length rat $\mathrm{N}$-cadherin cDNA (generously provided by Prof. Masatoshi Takeichi, RIKEN Center for Developmental Biology, Kobe, Japan) was ligated into the pIRES2-AcGFP1 plasmid (Clontech). By engineering two unique restriction sites, XhoI and EcoRI, the N-cadherin gene was ligated into the vector. Overexpression was confirmed by immunostaining and Western blot for N-cadherin. DRG neurons were transfected using the Amaxa protocol for DRG neuron nucleofection (Lonza). Nucleofection typically resulted in the loss of $\sim 50 \%$ of the neurons; therefore, the density of the neurons was compensated by increasing the number of plated cells. Approximately 300,000 cells were plated per coverslip, rather than the typical 150,000 . DRG neurons were then purified and maintained for 2 weeks before SC seeding.

Mouse genotyping. Mice were cared for in accordance with animal protocols approved by the University of Southern California and were monitored by the University of Southern California Department of Animal Resources at Zilkha Neurogenetic Institute. Mice containing floxed $\mathrm{N}$-cadherin and $\beta$-catenin were obtained through The Jackson Laboratory. Dhh transgenic mice were generated at Erasmus Medical Center (Rotterdam, The Netherlands) and have been described previously (Jaegle et al., 2003). Mice were genotyped by PCR. Briefly, genomic DNA was isolated and standard PCRs were performed with the following primers: N-cadherin, forward, 5' -CCAAAGCTGAGTGTGACTTG-3'; N-cadherin, reverse, $5^{\prime}$-TACAAGTTTGGGTGACAAGC-3'; $\beta$-catenin, forward, $5^{\prime}$-AAGGTAGAGTGATGAAAGTTGTT- $3^{\prime} ; \beta$-catenin, reverse, $5^{\prime}$-CACCATGTCCTCTGTCTATTC-3'; Dhh, forward, 5' -ACCCTGTTACGTATAGCCGA-3'; Dhh, reverse, $5^{\prime}$-CTCCGGTATTGAAACTCCAG-3' ${ }^{\prime}$ N-cadherin primers amplified a DNA fragment of $290 \mathrm{bp}$ corresponding to the floxed allele and a 250 bp fragment corresponding to the wild-type allele. $\beta$-Catenin primers amplified a DNA fragment of $324 \mathrm{bp}$ corresponding to the floxed allele and a $221 \mathrm{bp}$ fragment corresponding to the wild-type allele. Dhh primers amplified a $300 \mathrm{bp}$ fragment from the DhhCre transgene as previously described (Jaegle et al., 2003). 
Immunoprecipitation, immunoblotting, and Western analysis. Samples from cocultures and rat/mouse sciatic nerves were prepared for immunoprecipitation and Western blot analysis as previously described (Yamauchi et al., 2003; Chan et al., 2006). Briefly, coimmunoprecipitation of $\mathrm{N}$-cadherin and $\beta$-catenin were performed on newborn rat sciatic nerves and from SC-DRG cocultures. Samples were dounced in lysis buffer containing the following: $50 \mathrm{~mm}$ Tris, $\mathrm{pH}$ 8.0, $150 \mathrm{~mm} \mathrm{NaCl}, 2 \mathrm{~mm}$ EDTA, $1 \mathrm{~mm} \mathrm{Na}_{3} \mathrm{VO}_{4}, 2.5 \mathrm{~mm} \mathrm{NaF}$, Complete protease inhibitor (Roche), 1\% NP-40, 0.5 Na-deoxycholic acid. SDS (0.1\%) was added to the lysis buffer when performing Western analysis. Samples were vortexed and supernatants were collected after centrifugation. Thirty microliters of protein A/G beads (Santa Cruz) and $2 \mu \mathrm{g}$ of antibody [mouse monoclonal anti$\mathrm{N}$-cadherin and mouse monoclonal anti- $\beta$-catenin (BD Biosciences Transduction Laboratories)] were added to the samples and allowed to rotate at $4^{\circ} \mathrm{C}$ overnight. Samples were washed three times in lysis buffer, resuspended in sample buffer with SDS and $\beta$-mercaptoethanol, and boiled for 2 min before loading. Electrophoretic separation of the samples and the extracts was performed on $10 \%$ discontinuous SDSpolyacrylamide gels. Proteins were transferred to nitrocellulose membranes and probed with specific antibodies. Antibodies for Western blot analysis were as follows: mouse monoclonal anti-N-cadherin (BD Biosciences Transduction Laboratories), mouse monoclonal anti- $\beta$ catenin (BD Biosciences Transduction Laboratories), rat monoclonal anti-MBP (Millipore Bioscience Research Reagents), mouse monoclonal anti-P0 (Astexx), mouse monoclonal anti- $\beta$-actin (Sigma-Aldrich), rabbit polyclonal anti-Oct-6 (Jaegle et al., 2003), and mouse monoclonal anti-myelin-associated glycoprotein (MAG) (Millipore Bioscience Research Reagents). The Alexa Fluor goat anti-rabbit, anti-mouse, and antirat $680 \mathrm{IgG}$ antibodies (Invitrogen) were used as secondary antibodies for near-infrared fluorescent detection performed on the Odyssey Infrared Imaging System (LI-COR).

Immunostaining. Immunostaining of purified SC cultures and SCDRG cocultures were performed as previously described ( $\mathrm{Ng}$ et al., 2007). Briefly, SC and SC-DRG cocultures were fixed using $4 \%$ paraformaldehyde, dehydrated, and permeabilized and blocked by incubation with $20 \%$ goat serum and $0.2 \%$ Triton X-100 in PBS. Myelin was detected with a rat monoclonal anti-MBP antibody (Millipore Bioscience Research Reagents). Axons were detected using a rabbit polyclonal antineurofilament (NF) antibody (145 kDa, medium chain) (Millipore) and a mouse anti-NF antibody ( $160 \mathrm{kDa}$, medium chain) (Serotec). SCs were detected by using a rabbit polyclonal antibody to S100 (Dako). Par-3 was detected using a rabbit polyclonal anti-Par-3 antibody (Millipore). $\mathrm{N}$-cadherin and $\beta$-catenin were detected by using a mouse monoclonal anti-N-cadherin antibody and a mouse monoclonal anti- $\beta$-catenin antibody (BD Biosciences Transduction Laboratories). p75 ${ }^{\text {NTR }}$ was detected using a rabbit polyclonal anti-p $75^{\text {NTR }}$ antibody (Promega). The Alexa Fluor anti-rat 594, anti-rabbit 488 and 594, and anti-mouse 488 and $594 \mathrm{IgG}$ antibodies (Invitrogen) were used as secondary antibodies for fluorescence detection. Cell nuclei were stained with mounting medium containing 4',6-diamidino-2-phenylindole (DAPI) (Vectashield; Vector Laboratories). Colocalization was determined by fluorescence microscopy combined with $Z$-stack acquisition and three-dimensional reconstruction performed on the Zeiss Apotome.

Sciatic nerve isolation and electron microscopy. Sciatic nerves from postnatal day 0 (P0), P5, P15, and adult animals were fixed through perfusion with $4 \%$ paraformaldehyde, and then submerged in $4 \%$ paraformaldehyde from $4 \mathrm{~h}$ to overnight. All nerves were stained with $1 \%$ osmium tetroxide for $1 \mathrm{~h}$ at $4^{\circ} \mathrm{C}$ and counterstained with $1 \%$ uranyl acetate overnight. Nerves were rinsed with distilled water and dehydrated in a series of ethanol dehydration treatments (50, 70, 95, and 100\% EtOH). Embedding was performed in a 1:1 resin (EMBed-812; Electron Microscopy Sciences) and propylene oxide (Electron Microscopy Sciences) mix for $1 \mathrm{~h}$ at room temperature, followed by a $2: 1$ resin/propylene oxide mix overnight at room temperature. Nerves were then placed in $100 \%$ resin for $3 \mathrm{~h}$ at room temperature. Ultrathin sections $(70 \mathrm{~nm})$ were obtained from the Norris Center Cell and Tissue Imaging Core at the University of Southern California, Keck School of Medicine, and visualized with a JEM1400 Electron Microscope (JEOL) in the Zilkha Neurogenetic Institute.

\section{Results}

\section{$\mathrm{N}$-cadherin and Par-3 colocalize at the SC-SC and} SC-axon interface

The expression of $\mathrm{N}$-cadherin was initially examined in purified DRG neurons, SCs, and SC-DRG cocultures (Fig. 1A). The SCDRG coculture system is instrumental for the observation of various stages preceding, during, and after active myelination. On contact with axons, SCs migrate and proliferate rapidly, occupying the available axonal space, before ensheathing and coordinating the length of myelin internodes. $\mathrm{N}$-cadherin expression is robustly detected in purified DRG neurons, SCs, and in the cocultures alike (Fig. $1 A$ ). SCs were seeded onto purified DRG neurons and allowed to proliferate and migrate for $7 \mathrm{~d}$ before the induction (I) of myelination with the addition of ascorbic acid. The expression of Oct-6, a transcription factor indicative of premyelinating SCs, initially increases because of the proliferation of SCs and then gradually decreases as myelination is initiated. Myelination is observed by the increase in the expression of the myelin-specific proteins, MAG and P0.

The polarity protein Par-3 is asymmetrically localized in SCs at the SC-SC and SC-axon interface (Fig. $1 B$ ). We hypothesize that the localization is initiated in similar fashion to the formation of apical domains of epithelial cells, where intercellular contact and focal adhesions recruit the Par complex to membrane specializations (PerezMoreno et al., 2003). These focal adhesions are formed by homotypic interactions of cadherin molecules. To investigate the possible role of $\mathrm{N}$-cadherin in the localization of Par-3, the expression of N-cadherin in purified SCs and in SC-DRG cocultures was analyzed and similarly localized to the SC-SC and SC-axon interface (Fig. 1C). By coimmunostaining for Par-3 and N-cadherin, we demonstrate colocalization of N-cadherin with Par-3 and partial colocalization of N-cadherin with Par-3 in SC-DRG cocultures at the SC-axon interface (Fig. 1D), indicating a potential role for $\mathrm{N}$-cadherin in the initiation of SC polarity and proper localization of Par-3.

The classic view of $\mathrm{N}$-cadherin is that it transduces signals through intracellular interactions with $\beta$-catenin, which in turn associates with $\alpha$-catenin, the actin cytoskeleton, as well as numerous adaptor proteins and transcription factors (Daniels et al., 2001; Ivanov et al., 2001). To determine whether $\beta$-catenin colocalizes with $\mathrm{N}$-cadherin and Par-3, we coimmunostained for $\beta$-catenin and Par-3 (Fig. $1 E$ ) and $\beta$-catenin and N-cadherin in SC-DRG cocultures (Fig. $1 F$ ). $\beta$-catenin colocalizes asymmetrically with both Par-3 and N-cadherin on SC-SC and SC-axon contact (data not shown). Furthermore, $\beta$-catenin and $\mathrm{N}$-cadherin associate with one another directly and can be coimmunoprecipitated from the developing sciatic nerves of newborn rat pups using antibodies to $\mathrm{N}$-cadherin and $\beta$-catenin (Fig. 1G). Additionally, $\mathrm{N}$-cadherin and $\beta$-catenin were coimmunoprecipitated in SC-DRG cocultures and clearly associate with one another throughout the myelination time course (Fig. $1 H, I)$. Intriguingly, this association was more robust after the induction of myelination by ascorbic acid, indicating a potential role for the association of $\mathrm{N}$-cadherin and $\beta$-catenin in the initiation of SC polarity and proper localization of Par-3. Together, the interaction of $\mathrm{N}$-cadherin with $\beta$-catenin in SCs suggests the formation of a classical, yet novel adherens junction between the SC and the axon.

\section{Knockdown of SC N-cadherin disrupts the asymmetric localization of Par-3 at the SC-axon interface and delays the initiation of myelination}

To determine the role of $\mathrm{N}$-cadherin in the asymmetric localization of Par-3, three different non-overlapping shRNA were designed and generated against $\mathrm{N}$-cadherin and coexpressed with GFP in a retroviral expression system (Fig. $2 A, C$ ). Since retrovi- 


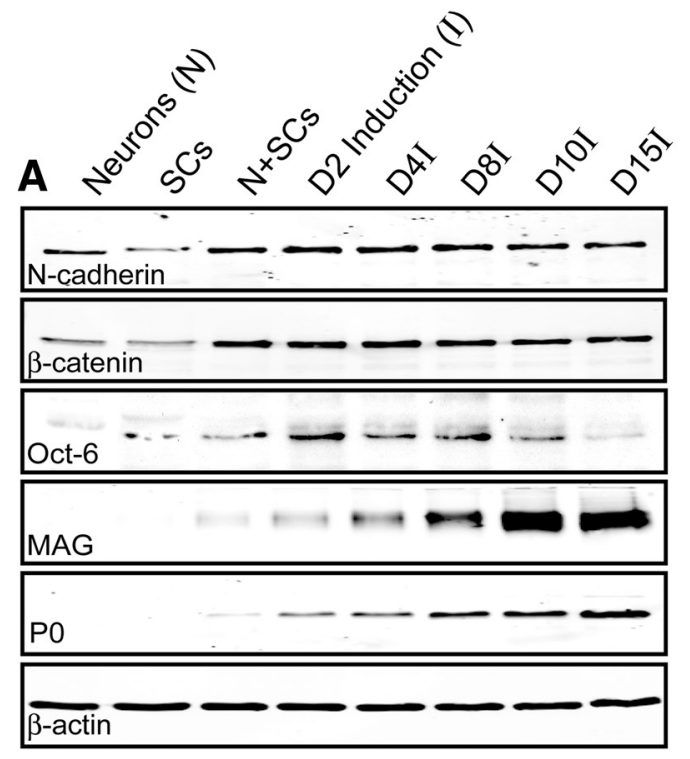

D

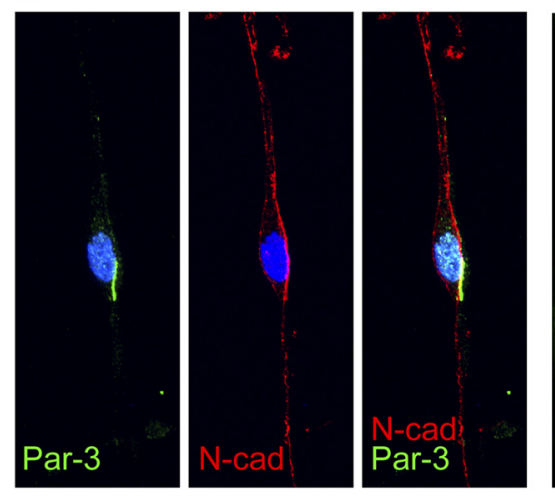

G Newborn Sciatic Nerves

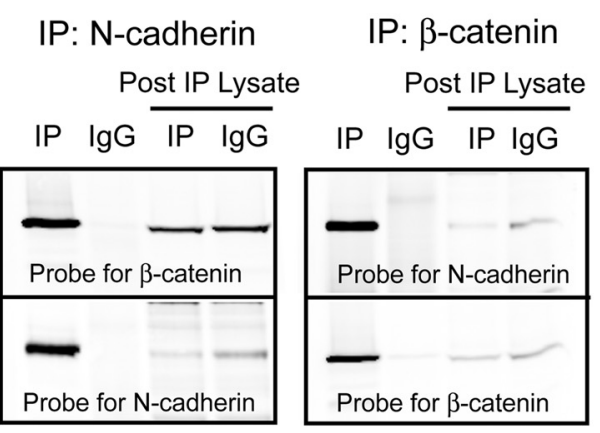

B

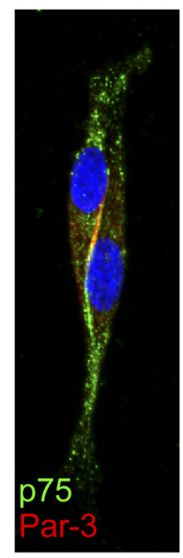

E

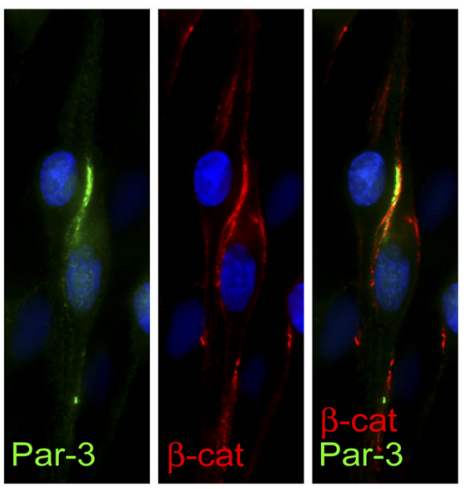

C

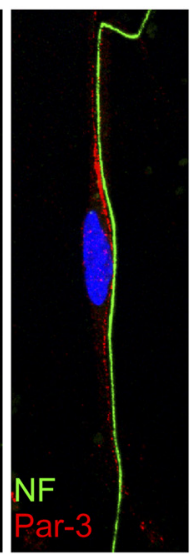

$\mathbf{F}$

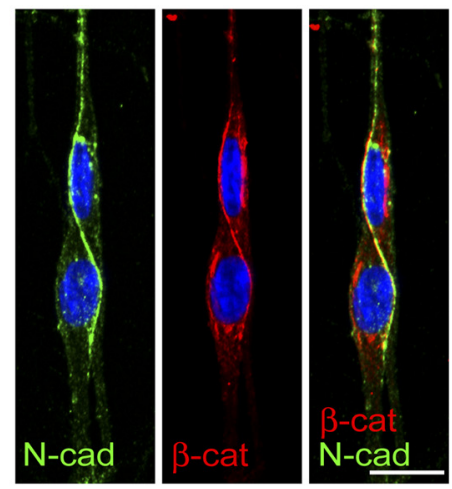

H IP for $\mathbf{N}$-cadherin I IP for $\beta$-catenin

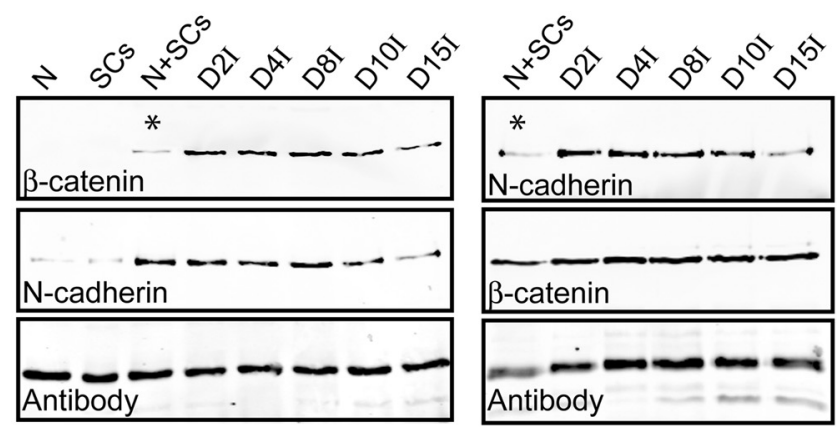

Figure 1. Expression and colocalization of Par-3 and N-cadherin in SCS. A, Western blot analysis of purified DRG neurons, SCS, and SC-DRG cocultures before (N+SCS) and after induction of myelination (denoted by I). Westerns blots were probed for $\mathrm{N}$-cadherin, $0 \mathrm{ct}-6$, a transcription factor expressed by premyelinating $\mathrm{SC}$, and myelin proteins (MAG and P0). $\beta$-Actin serves as a loading control. B, The polarity protein Par-3 (red) is asymmetrically localized on SC-SC and SC-axon contact. p75 ${ }^{\mathrm{NTR}}$ (green; first panel) is counterstained to identify the SCs and NF (green; second panel) for the axon. C, Similar to Par-3, N-cadherin (red) is asymmetrically localized on SC-SC and SC-axon contact. S100 (green; first panel) is counterstained to identify the SCs and NF (green; second panel) for the axon. The cell nuclei are detected by DAPI (blue). D, Par-3 and N-cadherin colocalize to the SC-axon interface in premyelinating SC-DRG cocultures. Par-3 (green) and N-cadherin (red) display asymmetric localization, and the merged image (third panel) displays colocalization (yellow). $\boldsymbol{E}$, Par-3 and $\beta$-catenin colocalize to the SC-axon interface in premyelinating SC-DRG cocultures. Par-3 (green) and $\beta$-catenin (red) display asymmetric localization, and the merged image (third panel) displays colocalization (yellow). $\boldsymbol{F}$, N-cadherin and $\beta$-catenin colocalize to the SC-axon interface in premyelinating SC-DRG cocultures. N-cadherin (green) and $\beta$-catenin (red) display asymmetric localization, and the merged image (third panel) displays colocalization (yellow). The nucleus is detected by DAPI (blue). Scale bars, $10 \mu \mathrm{m}$. G, N-cadherin and $\beta$-catenin coimmunoprecipitate in newborn rat sciatic nerves. $\beta$-Catenin coimmunoprecipitated with an antibody to $\mathrm{N}$-cadherin and was detected by immunoblotting with an antibody to $\beta$-catenin. $\mathrm{N}$-cadherin coimmunoprecipitated with an antibody to $\beta$-catenin and was detected by immunoblotting with an antibody to $\mathrm{N}$-cadherin. Normal lgGs were used as a control for the immunoprecipitation. The blots were stripped and reprobed with the antibody for each of the respective targets. The post-immunoprecipitation (IP) lysates were also probed to demonstrate depletion of the target and the respective binding partner. $\mathbf{H}, \mathbf{I}, \mathrm{N}$-cadherin and $\beta$-catenin coimmunoprecipitate in SC-DRG cocultures. The immunoprecipitation using either the $\mathrm{N}$-cadherin $(\boldsymbol{H})$ or $\beta$-catenin $(\boldsymbol{I})$ antibody clearly demonstrates a robust association, which is enhanced after the induction of myelination by ascorbic acid. The asterisks highlight the limited association between $\mathrm{N}$-cadherin and $\beta$-catenin before the induction of myelination. The lgG heavy chain illustrates the proper loading of the samples. 
A
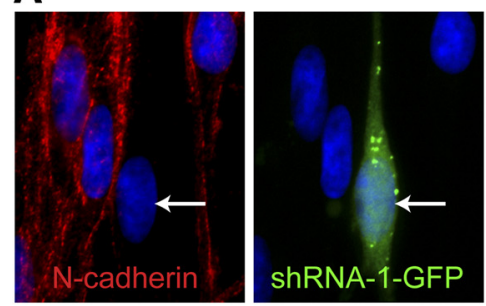

C

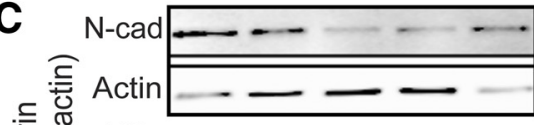

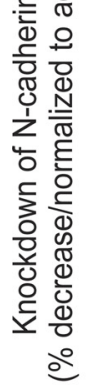

F

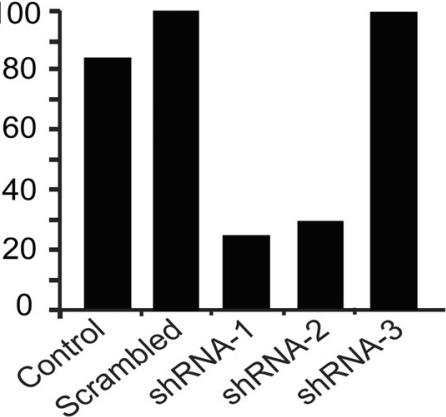

B

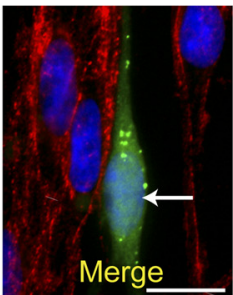

D

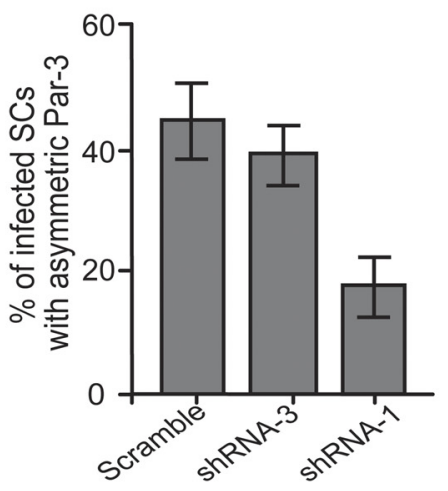

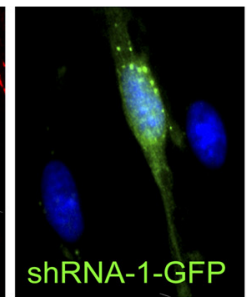

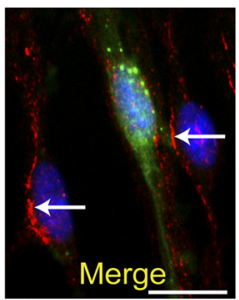

E

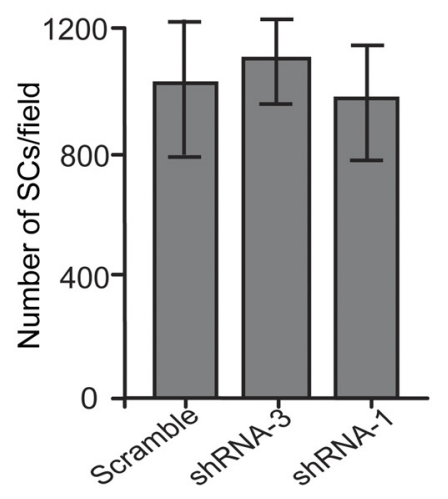

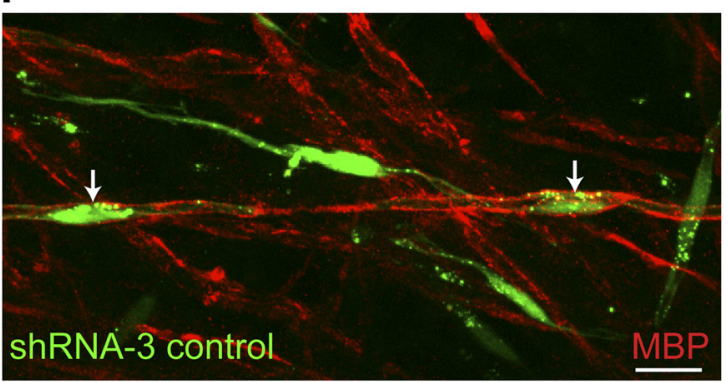

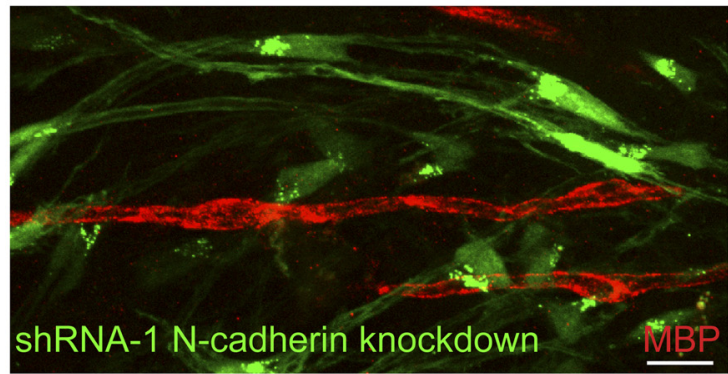

G

H
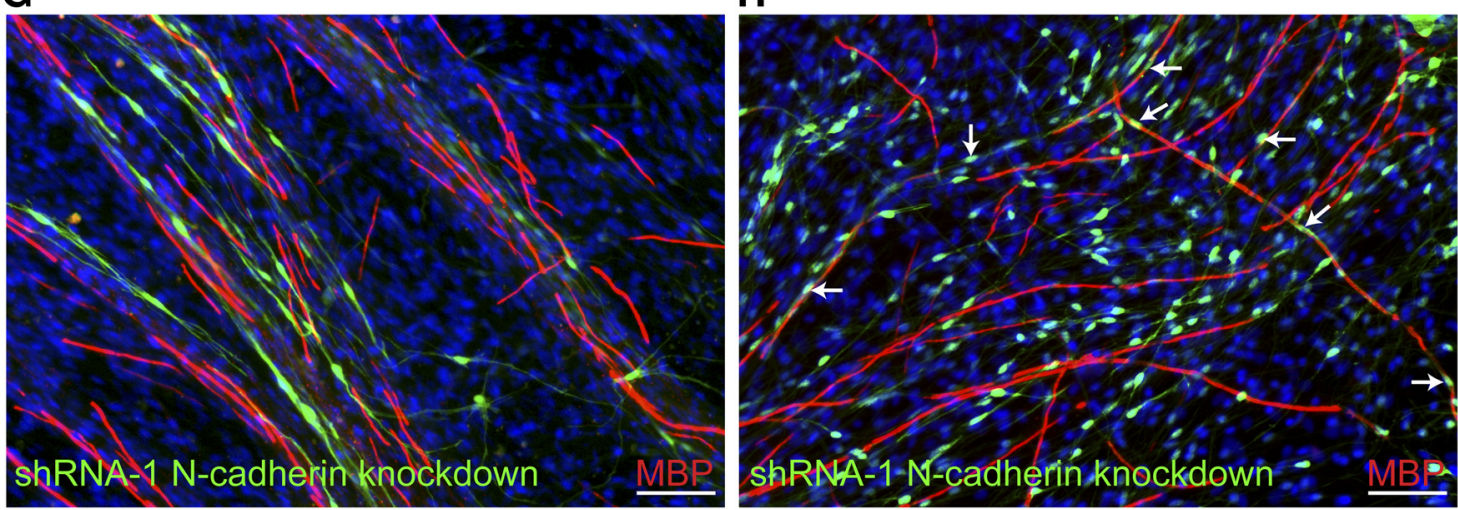

Figure 2. Knockdown of SCN-cadherin disrupts the asymmetric localization of Par-3 and delays the initiation of myelination. $A, S C-D R G$ cocultures were infected with retroviral vectors coexpressing GFP and the shRNA for N-cadherin. N-cadherin is detected by immunostaining (red), and SCs infected with shRNA-1 are identified by the expression of GFP (green). The arrow indicates an infected SC and the corresponding knockdown of N-cadherin. B,SC-DRG cocultures were infected with shRNA-1 against N-cadherin and stained for Par-3 (red). The arrows indicate uninfected SCs displaying asymmetric localization of Par-3, whereas Par-3 localization is disrupted in the SC expressing GFP. Scale bars, $10 \mu \mathrm{m}$. C, To determine the efficiency of knockdown with shRNA, purified SCs were infected with a control (GFP only), a scrambled shRNA, shRNA-1,-2, and -3. Cells were extracted and analyzed by Western blot analysis. Quantification of the Western blot is displayed as a percentage decrease normalized to $\beta$-actin. D, SCs infected with scrambled shRNA, shRNA-3 (control), and shRNA-1 against N-cadherin were quantified as a percentage of infected SCs that display asymmetric Par-3. Knockdown of N-cadherin using shRNA-1 results in a twofold decrease in the number of infected SCs displaying asymmetric Par-3. E, Manipulation of $\mathrm{N}$-cadherin expression does not have an appreciable effect on $\mathrm{SC}$ proliferation, as determined by the number of SCs per image field. Error bars indicate SD.F, G, Using SC-DRG cocultures, SCs were infected with either shRNA-3 (control) or shRNA-1 against N-cadherin and immunostained for MBP (red) $10 \mathrm{~d}$ after induction of myelination. Infected cells were indicated by the concomitant expression of GFP (green). The arrows indicate myelinating SCs expressing the control shRNA. SCs infected with shRNA-1 against N-cadherin did not form myelin as detected by MBP expression (red). Scale bars: $F, 10 \mu \mathrm{m} ; \boldsymbol{G}, \boldsymbol{H}, 50 \mu \mathrm{m}$. $\boldsymbol{H}$, After 15 d of induction of myelination, SCs infected with shRNA-1 were indistinguishable from the control cultures and were myelinating axons in similar proportions (red). The arrows indicate cells expressing GFP (green) and MBP (red), indicating that the knockdown of N-cadherin in SCs delays but does not inhibit the initiation of myelination. 
ral vectors infect only actively dividing cells, this method ensures that only SCs are infected whereas the DRG neurons remain unperturbed. Expression of N-cadherin was significantly attenuated by shRNA-1 and -2 as shown by immunostaining and Western blot analysis (Fig. 2A,C), whereas shRNA-3 did not alter expression, similar to uninfected cultures (control) or cultures infected with a scrambled shRNA. Knockdown of N-cadherin in SCs resulted in an approximate twofold decrease in the percentage of infected SCs displaying asymmetric localization of Par-3 at the SC-axon interface (Fig. 2B,D). In addition, manipulation of $\mathrm{N}$-cadherin expression did not alter SC alignment (Fig. 2A, $B$; supplemental Fig. 3, available at www.jneurosci.org as supplemental material) with axons and did not affect proliferation or migration of the SCs, as the number of SCs was unaffected in the cocultures (Fig. $2 \mathrm{E}$ ). These findings suggest a critical role for $\mathrm{N}$-cadherin and cell adhesion in the initiation of polarity in the SC.

Cadherins can recruit the Par complex directly, but can also indirectly recruit the Par complex through interactions with additional binding partners, such as Jam-1 and/or the nectins (Perez-Moreno et al., 2003; Wei et al., 2005). To determine whether N-cadherin could directly recruit Par-3 to the SC-axon interface, coimmunoprecipitation assays were conducted with antibodies against $\mathrm{N}$-cadherin and Par-3. In all of the experimental conditions analyzed the association of N-cadherin and Par-3 could not be detected, whereas positive controls for $\mathrm{N}$-cadherin ( $\beta$-catenin) and Par-3 (p75 NTR) (Chan et al., 2006) were clearly observed (data not shown). Therefore, although SC N-cadherin expression is essential for the asymmetric localization of Par-3, the molecular mechanism responsible for the recruitment of Par-3 to the SC-axon interface remains unclear.

Although previous studies demonstrate the importance of $\mathrm{N}$-cadherin in SC proliferation, migration, and early SC-axon interactions (Wanner and Wood, 2002; Wanner et al., 2006; Gess et al., 2008), its specific role in the initiation of myelination remains uncertain. To determine the function of $\mathrm{N}$-cadherin in SC myelination, shRNA to N-cadherin was expressed in SCs, and myelination in SC-DRG cocultures was analyzed $10 \mathrm{~d}$ after induction with ascorbic acid (Fig. 2 F). Typically, robust SC myelination is detected $10 \mathrm{~d}$ after addition of ascorbic acid, represented by the maximal expression of myelin proteins as a percentage of the total protein (Fig. 1A). SCs infected with control shRNA (GFP) formed myelin segments similar to the control cultures. Approximately $10 \%$ of the SCs infected with the scrambled or control shRNA formed myelin segments as indicated by the expression of MBP. However, knockdown of N-cadherin resulted in a twofold reduction in the percentage of myelinating SCs after $10 \mathrm{~d}$ of induction (Fig. $2 \mathrm{~F}, \mathrm{G}$; supplemental Fig. $1 \mathrm{~A}$, available at www.jneurosci.org as supplemental material). To further determine the essential nature of N-cadherin and whether SCs lacking $\mathrm{N}$-cadherin are simply delayed, we analyzed cocultures $15 \mathrm{~d}$ after induction by ascorbic acid. Interestingly, after the additional $5 \mathrm{~d}$ of induction, SCs infected with the shRNA to N-cadherin formed myelin normally and at a similar percentage to the control cultures (Fig. $2 \mathrm{H}$; supplemental Fig. $1 \mathrm{~A}$, available at www.jneurosci.org as supplemental material). Together, knockdown of $\mathrm{N}$-cadherin in SCs delays myelination in vitro, without affecting SC alignment, migration, or proliferation. Therefore, $\mathrm{N}$-cadherin is not an essential component in the formation of myelin, but instead functions to polarize the SC and initiate myelination in a timely manner.

\section{The asymmetric localization of Par-3 in SCs does not depend} on the expression of neuronal $\mathrm{N}$-cadherin

Cadherins are a family of adhesion proteins that interact homotypically to promote the formation of adherens junctions. To disrupt the homotypic interactions of $\mathrm{N}$-cadherin in SC-axon interactions, purified DRG neurons were infected with shRNA against $\mathrm{N}$-cadherin using a lentiviral expression system (Fig. $3 A$ ). Knockdown of $\mathrm{N}$-cadherin was observed in purified neurons coexpressing shRNA-1 and GFP as detected by immunostaining for $\mathrm{N}$-cadherin (Fig. $3 A$ ). One week after infection, purified SCs were seeded onto the neurons, which began to proliferate and migrate along the axons normally (Fig. $3 F$ ). Two days after induction of myelination, the SCs that were aligned along GFP-positive axons were examined for Par-3 localization (Fig. $3 B, C$ ). Surprisingly, knockdown of $\mathrm{N}$-cadherin in the neurons did not affect the distribution of Par-3 at the SC-axon interface. Additionally, the expression of neuronal $\mathrm{N}$-cadherin did not alter SC myelination even at $10 \mathrm{~d}$ after induction as indicated by the expression of MBP (Fig. $3 D$, E; supplemental Fig. $1 B$, available at www.jneurosci.org as supplemental material). Although the results do not reach statistical significance, knockdown of $\mathrm{N}$-cadherin in the axons resulted in robust myelination and in some cases augmented the number of myelin segments formed. These findings prompted an investigation into the overexpression of $\mathrm{N}$-cadherin in purified DRG neuronal cultures (Fig. $3 G$ ). The full-length rat N-cadherin was transfected using Amaxa Nucleofection and coexpressed with GFP in a mammalian expression vector containing an internal ribosomal entry site (IRES). Three weeks after nucleofection of the neurons, SCs were seeded and induced to form myelin for 10 d. Similar to the knockdown studies, neuronal N-cadherin expression did not reduce or enhance the number of myelin segments formed (Fig. 3H; supplemental Fig. 1C, available at www. jneurosci.org as supplemental material). These findings suggest that homotypic interactions between SC and axonal N-cadherin do not play a significant role in the localization of Par-3 at the SC-axon interface and do not alter any of the events surrounding the initiation or formation of the myelin sheath.

\section{SC-specific deletion of $\mathrm{N}$-cadherin delays myelination in vivo}

Although the in vitro studies presented suggest that the expression of N-cadherin in SCs may be important for the initiation of myelination, confirming these results in an in vivo setting is essential. To specifically ablate $\mathrm{N}$-cadherin in SCs, mice possessing loxP sites flanking exon 1 of the $\mathrm{N}$-cadherin gene (Flox) (The Jackson Laboratory) were crossed with transgenic mice expressing Cre recombinase (Cre) under the control of the Desert hedgehog (Dhh) regulatory sequences (Jaegle et al., 2003). The expression of N-cadherin in SCs from knock-out mice (Dhh$\mathrm{Cre}^{+/-}$, Flox-N-cad/Flox-N-cad) and littermate controls (Dhh$\mathrm{Cre}^{-/-}$, Flox-N-cad $\left.{ }^{+/-}\right)$was examined at embryonic days 13, 15, and 18 (supplemental Fig. $2 A, B$, available at www.jneurosci. org as supplemental material; Fig. $4 A, B)$ and was dramatically reduced by day 18 . Cocultures were also established and SC alignment and process extension were essentially unaffected (supplemental Fig. 3, available at www.jneurosci.org as supplemental material). Additionally, expression of $\mathrm{N}$-cadherin was examined in the sciatic nerves from postnatal day 5 through adulthood by Western analysis (Fig. 5A). Compared with littermate controls, the SC-specific knock-out mice displayed a dramatic reduction. At postnatal day 5, the expression of $\mathrm{N}$-cadherin detected in the sciatic nerves of the knock-out mice was attributed to axonal expression (data not shown). Concomitantly, the expression of Oct-6, a transcription factor indicative of premyelinating SCs, 
A
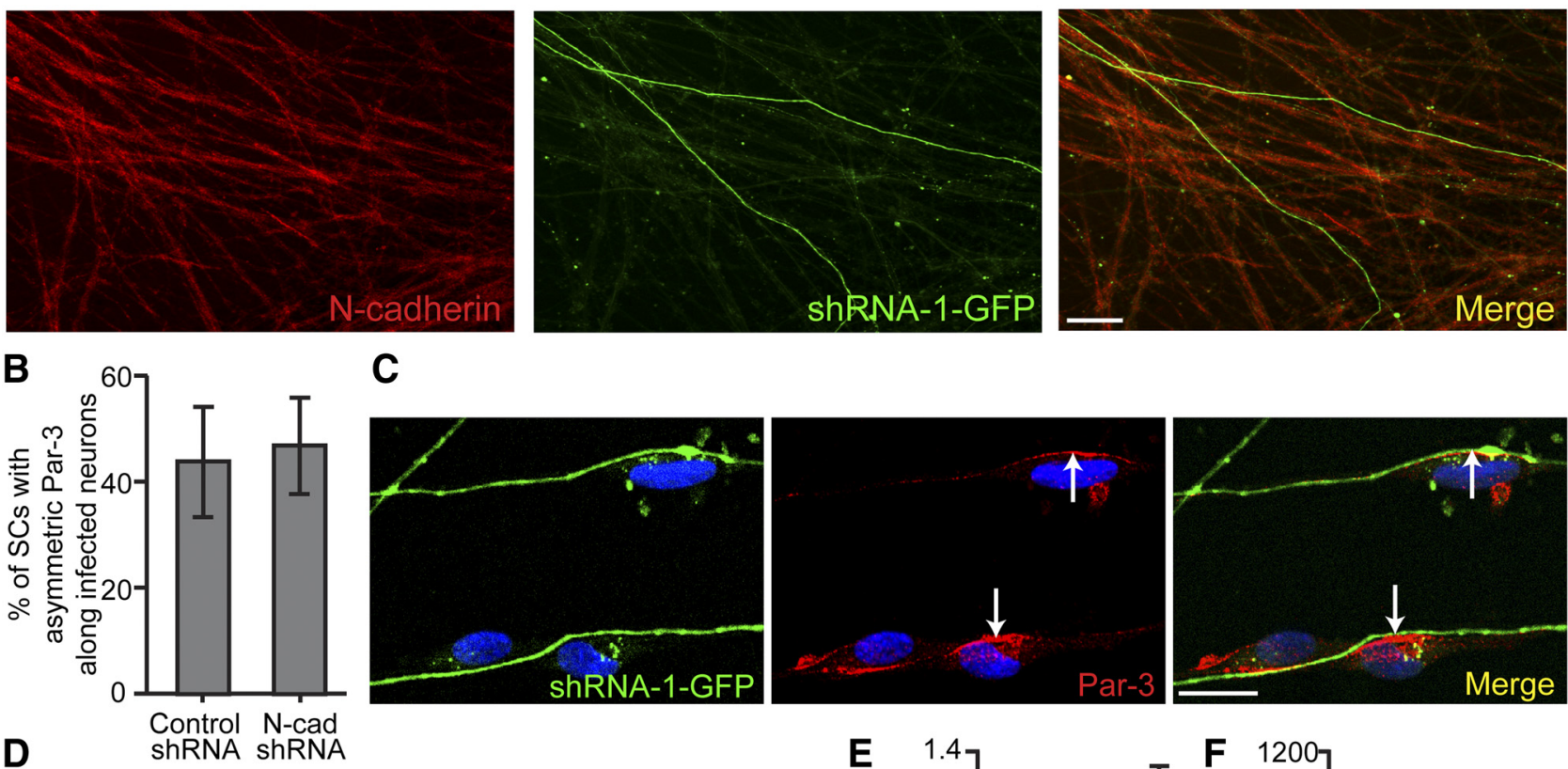

C
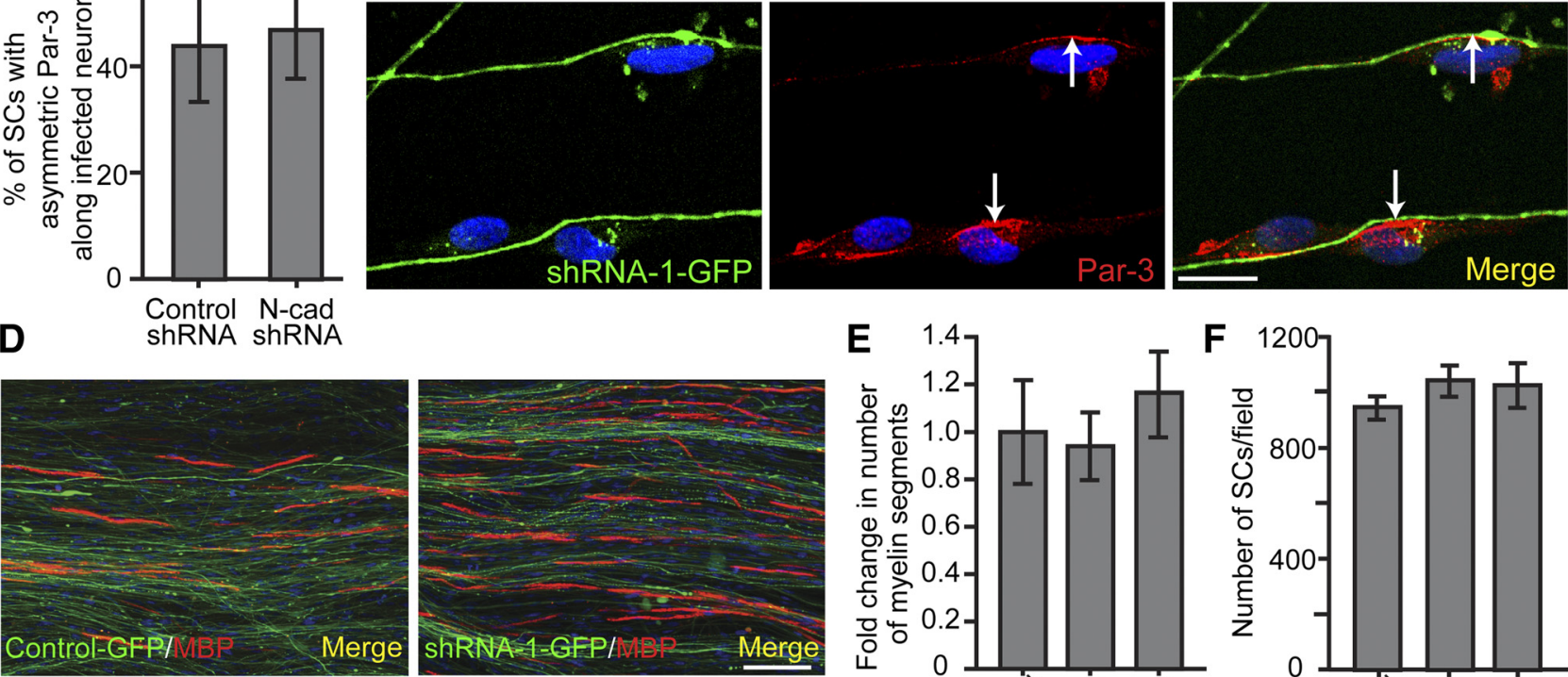

D
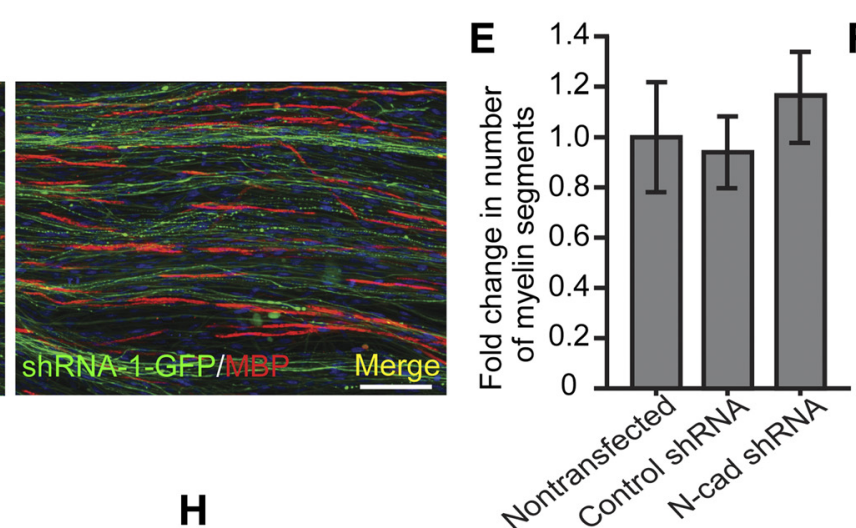

F 1200
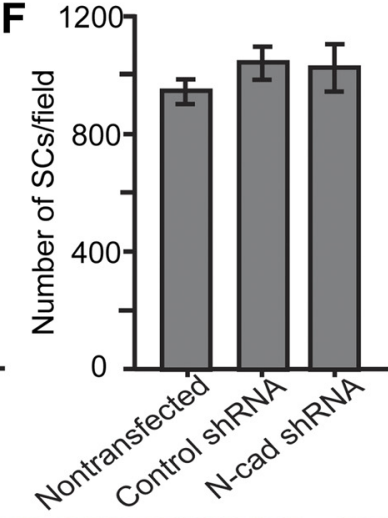

G

H

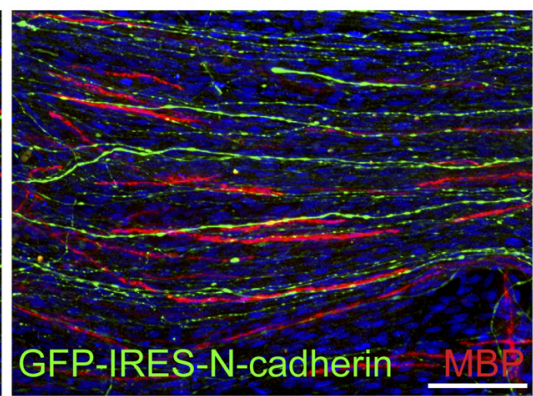

Figure 3. Par-3 localization and myelination are not dependent on the expression of neuronal N-cadherin. $A$, Purified DRG cultures were infected with a lentiviral vector coexpressing GFP and the shRNA for N-cadherin. N-cadherin is detected by immunostaining (red) and infected neurons are identified by the expression of GFP (green). Scale bar, $20 \mu \mathrm{m}$. $\boldsymbol{B}, \mathrm{Knockdown}$ of neuronal N-cadherin does not alter the asymmetric localization of Par-3 in SCs. Quantification is displayed as the percentage of SCs along infected neurons displaying asymmetric Par-3 in both control and shRNA-1 against $\mathrm{N}$-cadherin. C, SC-DRG cocultures displaying knockdown of neuronal N-cadherin were immunostained for Par-3 (red). The arrows indicate asymmetric Par-3 at the SC-axon interface. Scale bar, 10 $\mu \mathrm{m} . \boldsymbol{D}, \mathrm{SC}-\mathrm{DRG}$ cocultures displaying knockdown of neuronal N-cadherin were induced to form myelin for $10 \mathrm{~d}$ and immunostained for MBP (red). Scale bar, $50 \mu \mathrm{m}$. $E$, Quantification showing the fold change in number of myelin segments between transfected cocultures, normalized to nontransfected cocultures. $\boldsymbol{F}$, Manipulation of neuronal N-cadherin expression does not have an appreciable effect on SC proliferation, as determined by the number of SC s per image field. Error bars indicate SD. G, DRG cultures were transfected with AcGFP-IRES vector containing GFP and an IRES used to overexpress $\mathrm{N}$-cadherin by Amaxa nucleofection. DRGs were immunostained for $\mathrm{N}$-cadherin (red), and transfected cells were identified by GFP expression (green). Scale bar, $50 \mu \mathrm{m}$. $\boldsymbol{H}$, SC-DRG cocultures displaying overexpression of neuronal N-cadherin were induced to myelinate for $10 \mathrm{~d}$ and immunostained for MBP (red). Transfected cells were identified by GFP expression (green), and nuclei were detected by DAPI (blue). Scale bar, $50 \mu \mathrm{m}$.

remained unchanged, illustrating that early SC events (differentiation, proliferation, and migration) were unperturbed by the $\mathrm{N}$-cadherin deletion. Furthermore, the myelin-specific proteins, MBP and P0, were analyzed and compared between the mice. Although the expression of MBP and P0 were clearly detectable, the SC-specific knock-out nerves displayed a delay and reduction in the expression of the myelin proteins at postnatal days 5 and 10 (Fig. 5A). On examination of the sciatic nerves by electron microscopy, myelinated axons were clearly identified at every stage of postnatal development without any observable defects in axonal sorting, compaction, or myelin extent (Fig. 5C). Additionally, the number of SCs and axons were unaffected in the 

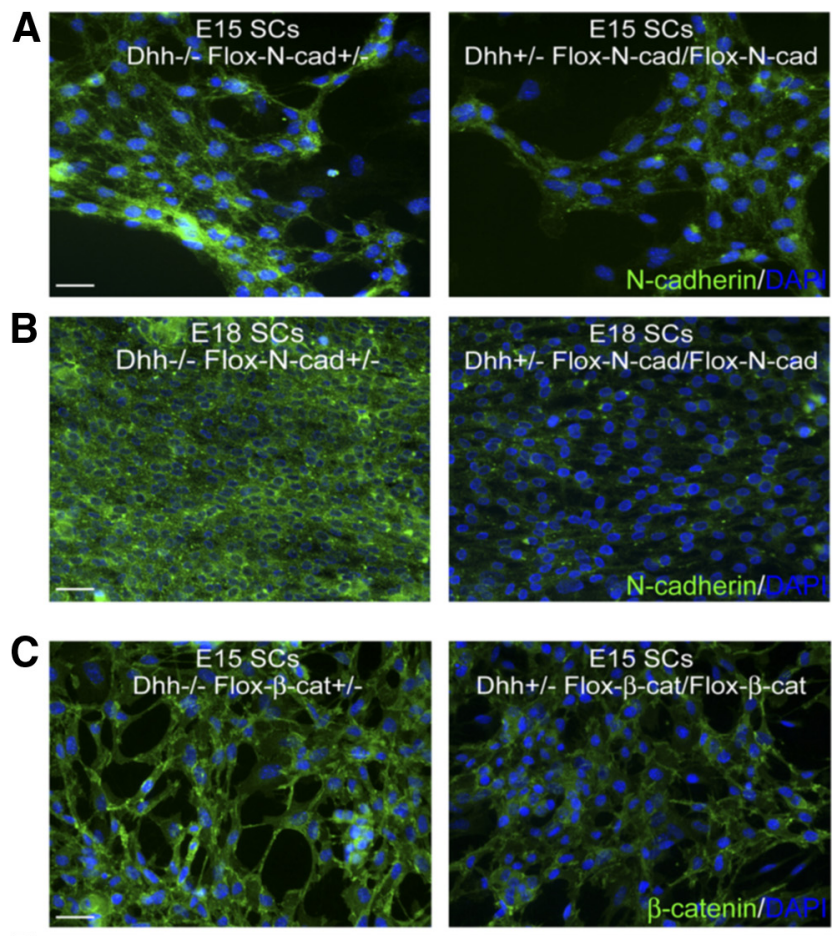

D
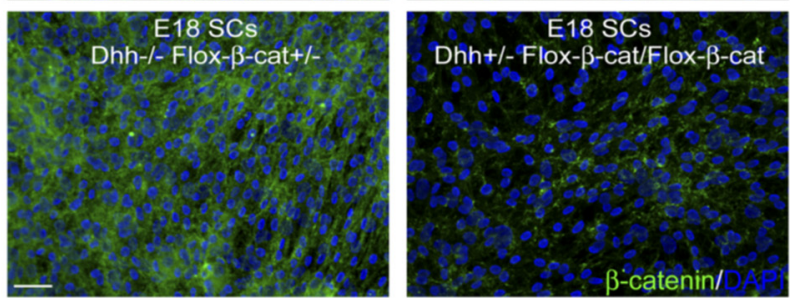

Figure 4. Determination of Dhh-Cre recombination efficiency in floxed N-cadherin and $\beta$-catenin mice. $\boldsymbol{A}, \mathrm{SCS}$ were isolated and analyzed for $\mathrm{N}$-cadherin expression from $\mathrm{Dhh}^{-1-}$ Flox-N-cad ${ }^{+/-}$and Dhh ${ }^{+/-}$Flox-N-cad/Flox-N-cad mice at E15 (littermates). Although the expression of $\mathrm{N}$-cadherin was still detectable, it was significantly diminished. $\boldsymbol{B}$, Expression of $\mathrm{N}$-cadherin in SCs from E18 littermates was essentially undetectable (similar to background fluorescence). C, SCs were isolated and analyzed for $\beta$-catenin expression from Dhh ${ }^{-1-}$ Flox$\beta$-cat ${ }^{+/-}$and Dhh ${ }^{+/-}$Flox- $\beta$-cat/Flox- $\beta$-cat mice at E15 (littermates). Similar to $\mathrm{N}$-cadherin, the expression of $\beta$-catenin was still detectable but was significantly diminished. D, Expression of $\beta$-catenin in SCs from E18 littermates was essentially undetectable (similar to background fluorescence). $\mathrm{N}$-cadherin and $\beta$-catenin staining is identified in green and cell nuclei are in blue (DAPI). Scale bars, $20 \mu \mathrm{m}$.

SC-specific knock-out of N-cadherin. The only detectable difference that reached statistical significance was the modest reduction in the number of myelinated axons observed at postnatal day 0 (Fig. 5B). Although the results demonstrate that SC $\mathrm{N}$-cadherin is a nonessential component for the formation, maintenance, and extent of the myelin sheath, the findings are nevertheless consistent with the in vitro data suggesting that $\mathrm{N}$-cadherin may be an important component required to initiate myelination in a timely manner.

\section{SC-specific deletion of $\beta$-catenin delays myelination in vivo}

Since $\beta$-catenin is a known effector of $\mathrm{N}$-cadherin and associates with $\mathrm{N}$-cadherin at the SC-axon interface (Fig. $1 F-I$ ), we set out to determine whether $\beta$-catenin could be responsible for a possible compensatory mechanism on the $\mathrm{N}$-cadherin deletion. To specifically ablate $\beta$-catenin in SCs, mice possessing loxP sites flanking a region of gene sequence from exon 2 to exon 6 of the $\beta$-catenin gene (The Jackson Laboratory) were crossed with transgenic mice expressing Cre recombinase under the control of
Dhh. SC-DRG cocultures were initially established from knockout mice (Dhh-Cre ${ }^{+/-}$, Flox- $\beta$-cat/Flox- $\beta$-cat) and littermate controls (Dhh-Cre ${ }^{-1-}$, Flox- $\beta$-cat ${ }^{+/-}$) at $15 \mathrm{~d}$ gestation, and myelination was analyzed in vitro. Similar to the $\mathrm{N}$-cadherin studies, SC alignment and process extension were unaffected (supplemental Fig. 4, available at www.jneurosci.org as supplemental material), and although the onset of myelination was delayed in the $\beta$-catenin knock-out cultures after $10 \mathrm{~d}$ of induction (Fig. $6 B$ ), the number of myelin segments was recovered after an additional $5 \mathrm{~d}$ in vitro (Fig. $6 A, B$; supplemental Fig. $1 D$, available at www.jneurosci.org as supplemental material). Additionally, the expression of $\beta$-catenin in SCs was examined at embryonic days 13,15 , and 18 (supplemental Fig. $2 C, D$, available at www. jneurosci.org as supplemental material; Fig. $4 C, D$ ) and in the sciatic nerves from postnatal day 5 through adulthood by Western analysis (Fig. 6C). Compared with littermate controls (Dhh$\mathrm{Cre}^{-/-}$, Flox- $\beta$-cat ${ }^{+/-}$), the SC-specific knock-out mice (Dhh$\mathrm{Cre}^{+/-}$, Flox- $\beta$-cat/Flox- $\beta$-cat) displayed a dramatic reduction in the expression of $\beta$-catenin starting at embryonic day 18 (Fig. $4 D)$. Concomitantly, the expression of the myelin-specific proteins, MBP and P0, from sciatic nerves, were analyzed and compared between the mice. The SC-specific knock-out nerves displayed a delay and reduction in the expression of the myelin proteins at postnatal days 5 and 10 (Fig. 6C). The expression of Oct-6 remained unchanged, illustrating that early SC events (differentiation, proliferation, and migration) were unperturbed by the $\beta$-catenin deletion. On examination of the sciatic nerves by electron microscopy, myelinated axons were clearly identified at every stage of postnatal development without any observable defects in axonal sorting, compaction, or myelin extent (Fig. $6 E$ ). Furthermore, the number of SCs and axons were unaffected in the SC-specific knock-out of $\beta$-catenin. The only detectable difference that reached statistical significance was the reduction in the number of myelinated axons observed at postnatal days 0 and 5 (Fig. $6 D, E$ ), displaying a more severe delay than when manipulating $\mathrm{N}$-cadherin. Although the results suggest that $\mathrm{SC}$ $\beta$-catenin may compensate for the delay in myelination in the absence of $\mathrm{N}$-cadherin, our findings clearly demonstrate that neither molecule is necessary for the formation, maintenance, and extent of the myelin sheath.

\section{Discussion}

Myelination is a unique example of cell-cell interaction, whereby a cell wraps multiple layers of its own membrane around a neuronal axon to maximize the efficiency of the functioning neuron. How is this fascinating process initiated and both spatially and temporally regulated? Here, we hypothesize that cell adhesion through cell-cell contact, specifically mediated by the homotypic interactions between SC and axonal N-cadherin initiates cell polarity and the asymmetric localization of Par-3, leading to myelination. Although the Par proteins were first identified in Caenorhabditis elegans (Rose and Kemphues, 1998), they are remarkably conserved across various model organisms and cell types, illustrating a truly unique intrinsic program that directs specified function in highly dynamic environments (Rose and Kemphues, 1998; Hutterer et al., 2004; Le Bivic, 2005). The Par proteins form a complex, consisting of Par-3, Par-6, and aPKC (atypical protein kinase $\mathrm{C}$ ), all of which are evolutionarily conserved and detected at the earliest stages of development, suggesting that they may function in recruiting essential factors and establishing membrane specializations (Hutterer et al., 2004; Le Bivic, 2005). The Par proteins are essential in establishing cell polarity in the SC, altering cytoskeletal dynamics, morphology, 
and localizing signaling cascades essential for myelination. In recent years, extrinsic growth factors, such as the neuregulins, have been shown to regulate SC development and myelination (Michailov et al., 2004; Taveggia et al., 2005). Specifically, Neuregulin-I (NRG1), expressed throughout development, interacts with the ErbB receptors on SCs to control migration, proliferation, and survival (Nave and Salzer, 2006). Although all NRG1 isoforms activate ErbB receptors on SCs, only the NRG1 type III isoform (membrane tethered) induces myelination and controls the thickness of the myelin sheath via the activation of PI-3 kinase (Michailov et al., 2004; Taveggia et al., 2005). The cellular mechanisms responsible for this specificity of function achieved by the different NRG1 isoforms remain undefined. Although great strides have been made to identify the environmental signals and receptors that control SC myelination, it has become evident that the intracellular signaling molecules and pathways involved are highly ubiquitous and govern a wide range of cellular processes. Could the intracellular mechanism for cell polarity control the activation, coordination, and organization of signaling pathways that specify function at the appropriate time?

Based on extensive research concerning the initiation of epithelial cell polarity, it is likely that the initiation of SC polarity is a direct result of cell-cell contact and the action of cell adhesion molecules, such as N-cadherin (Wanner and Wood, 2002; Wanner et al., 2006; Gess et al., 2008), Necls (Maurel et al., 2007; Spiegel et al., 2007), and integrins (Benninger et al., 2007; Nodari et al., 2007). These molecules may recruit Par-3 to the SC-axon interface, resulting in asymmetric localization and cytoskeletal reorganization by regulating actin and microtubule dynamics. Par-3 can regulate the Rho-family GTPases through GEFs (guanine nucleotide exchange factors) to mediate actin reorganization and possibly control axonal sorting and the unidirectional ensheathment of the axon (Benninger et al., 2007; Bryan and D'Amore, 2007; Nodari et al., 2007). Additionally, during asymmetric cell division, Par-3 recruits proteins such as Inscuteable, which in turn recruits Partner of Inscuteable (Pins) (Cai et al., 2003; Siller et al., 2006). Pins directly associates with heterotrimeric G-protein subunits and microtubuleassociated proteins to dictate the orientation of the microtubules and their positioning along the cell cortex (Izumi et al., 2006; Siller et al., 2006; Morin et al., 2007; Konno et al., 2008). Could redundant mechanisms exist in the SC, whereby Par-3 recruits microtubule-associated proteins to position and ori-
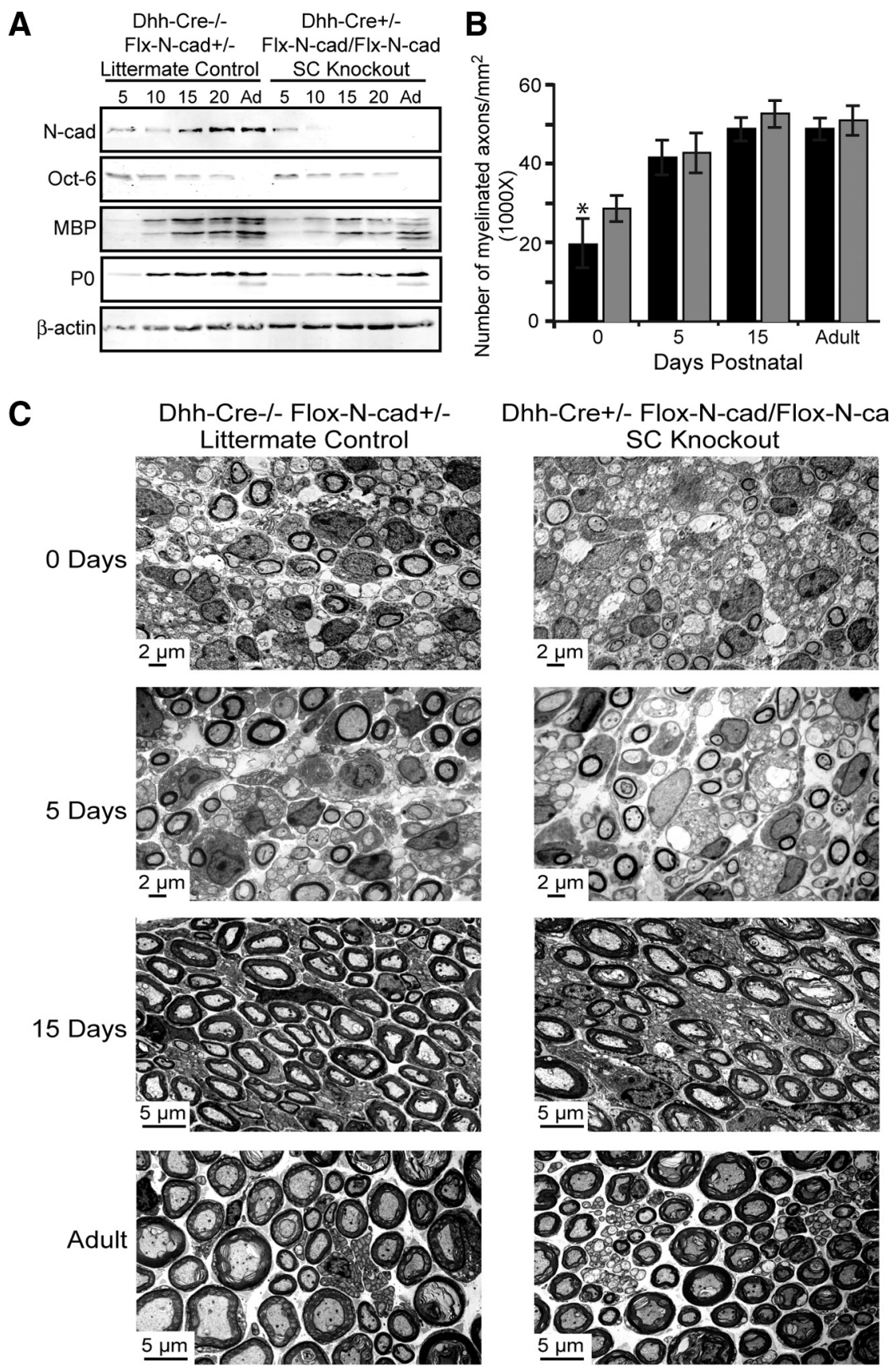

Figure 5. N-cadherin knock-out mice display a slight delay in myelination without impacting SC numbers, ensheathment, myelin structure, and compaction. $\boldsymbol{A}$, Western blot analysis was performed using mouse sciatic nerves from SC-specific knock-out mice (Dhh-Cre ${ }^{+/-}$, Flox-N-cad/Flox-N-cad) and littermate controls (Dhh-Cre ${ }^{-1-}$, Flox-N-cad ${ }^{+/-}$). Westerns were probed for $\mathrm{N}$-cadherin, $0 \mathrm{ct}-6, \mathrm{MBP}, \mathrm{PO}$, and $\beta$-actin (loading control). $\boldsymbol{B}$, Myelination in knock-out and control mice was quantified as the number of myelinated axons per square millimeter. The black columns represent the knock-out nerves, and the gray columns are the littermate controls. Nerves from three separate mice were analyzed, and the values are displayed as the mean number of myelinated axons \pm SD. Significance was evaluated using Student's $t$ test $\left(^{*} p<0.05\right)$. C, The number of Schwann cells, axonal sorting, compaction, and extent of myelination were examined by electron microscopy of knock-out and control mouse sciatic nerves at $0,5,15 \mathrm{~d}$ postnatal and adult nerves.

ent microtubules so that polymerization may lead to elongation, membrane spreading, and/or proper positioning of the SC as ensheathment initiates? Par-3 likely controls the activation of downstream signaling pathways by the recruitment to, or sequestration from, the SC-axon interface. This reorganization may dictate the accessibility of proteins for localized signaling and ensures that their activation occurs in a spatially and temporally appropriate manner. 
A

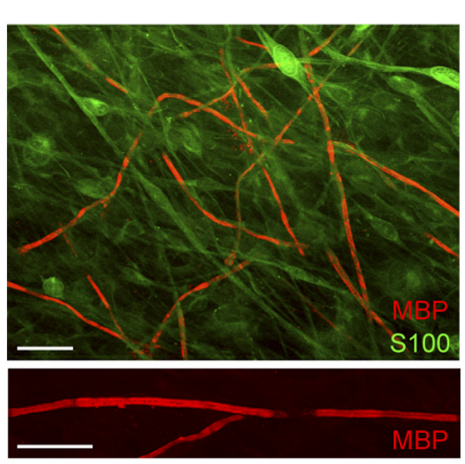

C

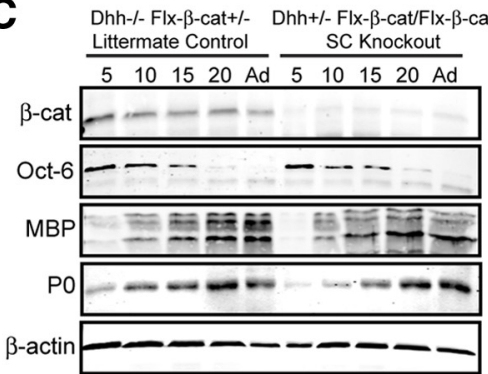

E

Days

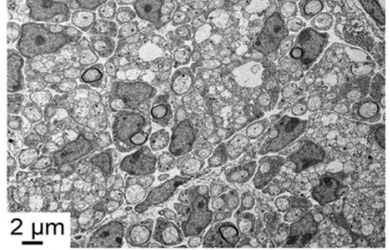

Dhh-/- Flox- $\beta$-cat+/Littermate Control

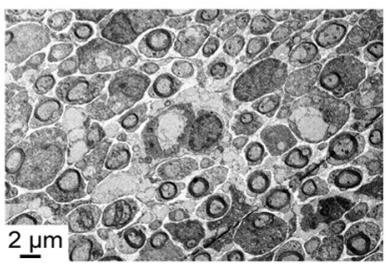

5 Days

15 Days
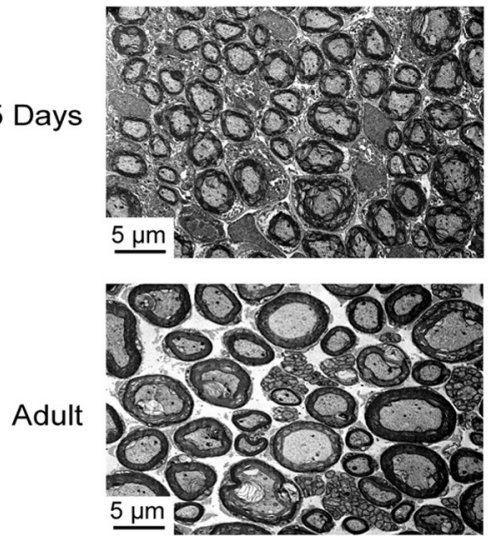

$\mathbf{B}$

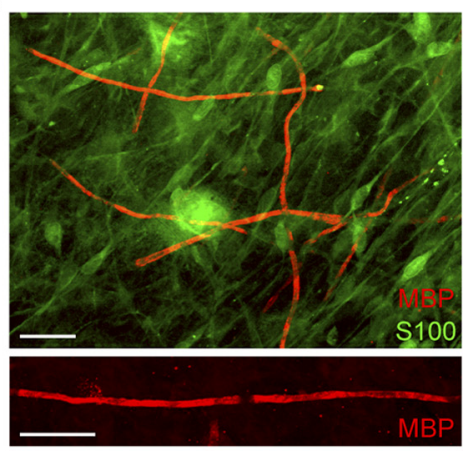

D

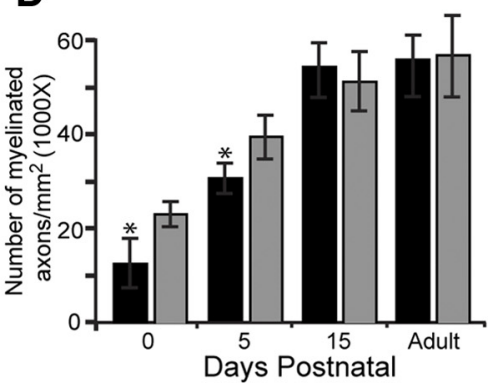

Dhh+/- Flox- $\beta$-cat/Flox- $\beta$-cat SC Knockout
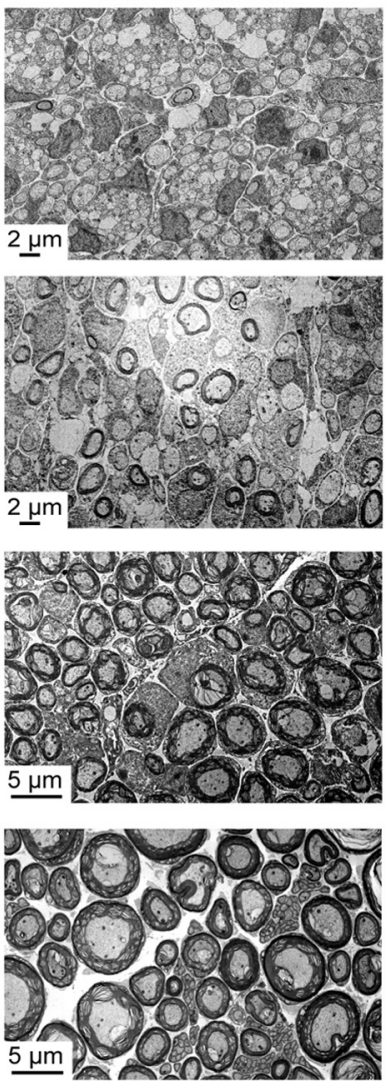

Figure 6. $\quad \beta$-Catenin knock-out mice display a more severe delay in myelination without impacting $\mathrm{SC}$ numbers, ensheathment, myelin structure, and compaction. $\boldsymbol{A}, \boldsymbol{B}, \mathrm{SC}-\mathrm{DRG}$ cocultures were established from SC-specific $\beta$-catenin knock-out mice $(\boldsymbol{B})$

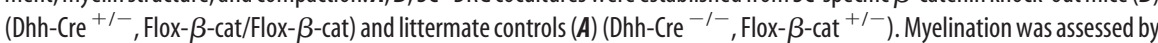
immunostaining for MBP (red) and S100 (green) $10 \mathrm{~d}$ after induction of myelination. The bottom panels illustrate magnified views of myelin internodes formed by SCs from both mice. Scale bar, $20 \mu \mathrm{m}$. C, Western blot analysis was performed using mouse sciatic nerves from SC-specific knock-out mice and littermate controls. Westerns were probed for $\beta$-catenin, $0 \mathrm{ct}-6, \mathrm{MBP}, \mathrm{P0}$, and $\beta$-actin (loading control). D. Myelination in knock-out and control mice was quantified as the number of myelinated axons per square millimeter. The black columns represent the knock-out nerves, and the gray columns are the littermate controls. Nerves from three

To determine the molecular mechanism responsible for the asymmetric localization of Par-3, we set out to identify adhesion molecules that form homotypic interactions and are localized on both the SC and the axon. The adhesion molecule $\mathrm{N}$-cadherin is a likely candidate, in that it plays essential roles in proliferation, in migration, and in early SC-axon interactions (Wanner and Wood, 2002; Wanner et al., 2006; Gess et al., 2008). It is important to note that the principal objective of this manuscript is to examine the role of $\mathrm{N}$-cadherin in the establishment of cell polarity and the initiation of myelination. Additionally, since Dhh-Cre-mediated recombination only partially ablates $\mathrm{N}$ cadherin expression at E13 and E15, conclusions concerning the role of $\mathrm{N}$-cadherin or $\beta$-catenin in early SC development remain uncertain (supplemental Fig. 2, available at www.jneurosci.org as supplemental material; Fig. 4). To characterize and manipulate the expression and localization of $\mathrm{N}$-cadherin in both SCs and DRG neurons, we used retroviral and lentiviral expression systems using purified SCs and DRG neurons in an in vitro coculture system for myelination. In this study, we focus our efforts on the role of N-cadherin in the establishment of cell polarity and the initiation of myelination. We find that $\mathrm{N}$-cadherin and Par-3 colocalize and that the asymmetric localization is induced on SC-SC and SCaxon contact. Infecting SCs with retrovirus containing shRNA to $\mathrm{N}$-cadherin results in a specific knockdown of N-cadherin in SCs, disrupting Par-3 localization and delaying the initiation of myelination. However, knockdown of neuronal $\mathrm{N}$-cadherin by lentiviral transduction did not alter the redistribution of Par-3 in SCs nor did it elicit any observable effects on the initiation of myelination, inconsistent with the hypothesis that homotypic interactions by SC and neuronal $\mathrm{N}$-cadherin initiate polarity and myelination. Additionally, knockdown of $\mathrm{N}$-cadherin specifically in SCs or in neurons did not alter the alignment of SCs along axons (supplemental Fig. 3, available at www.jneurosci.org as supplemental material) or in the total number of SCs in vitro (Fig. $2 E$ ). These results are seemingly contradictory to findings by Gess et

$\leftarrow$

separate mice were analyzed, and the values are displayed as the mean number of myelinated axons \pm SD. Significance was evaluated using Student's $t$ test $\left({ }^{*} p<0.05\right)$. $\boldsymbol{E}$, The number of Schwann cells, axonal sorting, compaction, and extent of myelination were examined by electron microscopy of knock-out and control mouse sciatic nerves at $0,5,15 \mathrm{~d}$ postnatal and adult nerves. 
al. (2008) and Wanner and Wood (2002). However, it must be noted that the previous studies alter $\mathrm{N}$-cadherin function in both the neurons and the Schwann cells, and the specificity of altering calcium levels, function-blocking antibodies, and peptides is highly dependent on the effective concentrations used and may result in more dramatic outcomes. To confirm our in vitro findings concerning the role of $\mathrm{N}$-cadherin at the SC-axon interface, we generated mice displaying SC-specific gene ablation of $\mathrm{N}$-cadherin. We report that myelination in the developing sciatic nerve is only slightly delayed and that the mice are viable without any detectable myelination defects. Consistent with this finding, Par-3 localization was also examined in SCs from the N-cadherin and $\beta$-catenin knock-out mice at E18 and found to be asymmetric at the SC-axon interface (supplemental Fig. $5 A, B$, available at www.jneurosci.org as supplemental material), suggesting that knockdown of $\mathrm{N}$-cadherin or $\beta$-catenin results in a delay in the asymmetric localization of Par-3 that is eventually recovered. Together, our in vitro and in vivo approaches suggest that, although the cell adhesion molecule $\mathrm{N}$-cadherin may contribute to initial focal adhesion and polarity, it is a nonessential molecular component in the establishment of SC polarity and in the initiation and maturation of the myelin sheath. Furthermore, N-cadherin does not function via homotypic interactions between SCs and axons. Could N-cadherin function via SC-SC contact to assist in the spatial distribution of SCs along axons and in determining the initiation and length of the myelin internode? Although these results suggest the existence of compensatory mechanisms, ablation of E-cadherin, another member of the cadherin family, does not influence the formation of myelin by Schwann cells (Young et al., 2002). Alternatively, it has been proposed that fibroblast growth factor receptor may interact with $\mathrm{N}$-cadherin as a potential binding partner (Lom et al., 1998; Utton et al., 2001; Wanner et al., 2006). FGF receptor 3 is highly expressed in axons of the peripheral nervous system (Wanner et al., 2006) and may represent a novel potential mechanism for Schwann cell N-cadherin function. Additional investigation and identification of adhesion molecules that share similar functions to $\mathrm{N}$-cadherin in intercellular interactions will provide insight into the alternative conclusions and possible compensatory mechanisms behind these findings.

Recently, the nectin-like proteins (Necls) were identified as critical mediators of SC-axon adhesion and myelination (Maurel et al., 2007; Spiegel et al., 2007). Necl4 expressed by SCs is apposed to and binds Necll along axons. Disruption of this specific interaction inhibits the initiation of SC myelination. Nectins and Necls play important roles throughout development and promote cellular adhesion, migration, and polarization (Takai et al., 2003; Kakunaga et al., 2005). Additionally, both $\mathrm{N}$-cadherin and $\mathrm{Necl} 4$ are asymmetrically localized to the SC-axon interface (Maurel et al., 2007; Spiegel et al., 2007), and the possibility that the Necls may compensate for the absence of $\mathrm{N}$-cadherin will provide a fascinating hypothesis to pursue. A clear understanding of the conserved mechanisms that coordinate and integrate signaling pathways via the Par proteins provides a unique opportunity to investigate how localization of these proteins are able to govern such a wide range of interactions, albeit with cell-context specificity. To develop potential therapeutic approaches concerning PNS myelination, it will be essential to resolve the mechanisms SCs use to interpret and translate extrinsic signals into the initiation of myelination.

\section{References}

Benninger Y, Thurnherr T, Pereira JA, Krause S, Wu X, Chrostek-Grashoff A, Herzog D, Nave KA, Franklin RJ, Meijer D, Brakebusch C, Suter U, Relvas JB (2007) Essential and distinct roles for $\mathrm{cdc} 42$ and racl in the regulation of Schwann cell biology during peripheral nervous system development. J Cell Biol 177:1051-1061.

Bryan BA, D'Amore PA (2007) What tangled webs they weave: Rho-GTPase control of angiogenesis. Cell Mol Life Sci 64:2053-2065.

Cai Y, Yu F, Lin S, Chia W, Yang X (2003) Apical complex genes control mitotic spindle geometry and relative size of daughter cells in Drosophila neuroblast and pI asymmetric divisions. Cell 112:51-62.

Cayouette M, Raff M (2003) The orientation of cell division influences cellfate choice in the developing mammalian retina. Development 130: 2329-2339.

Chan JR (2007) Myelination: all about Rac 'n' roll. J Cell Biol 177:953-955.

Chan JR, Jolicoeur C, Yamauchi J, Elliott J, Fawcett JP, Ng BK, Cayouette M (2006) The polarity protein Par-3 directly interacts with p75NTR to regulate myelination. Science 314:832-836.

Daniels DL, Eklof Spink K, Weis WI (2001) Beta-catenin: molecular plasticity and drug design. Trends Biochem Sci 26:672-678.

Ezzat S, Zheng L, Winer D, Asa SL (2006) Targeting N-cadherin through fibroblast growth factor receptor-4: distinct pathogenetic and therapeutic implications. Mol Endocrinol 20:2965-2975.

Gess B, Halfter H, Kleffner I, Monje P, Athauda G, Wood PM, Young P, Wanner IB (2008) Inhibition of N-cadherin and beta-catenin function reduces axon-induced Schwann cell proliferation. J Neurosci Res 86:797-812.

Goldstein B, Macara IG (2007) The PAR proteins: fundamental players in animal cell polarization. Dev Cell 13:609-622.

Grignani F, Kinsella T, Mencarelli A, Valtieri M, Riganelli D, Grignani F, Lanfrancone L, Peschle C, Nolan GP, Pelicci PG (1998) High-efficiency gene transfer and selection of human hematopoietic progenitor cells with a hybrid EBV/retroviral vector expressing the green fluorescence protein. Cancer Res 58:14-19.

Hutterer A, Betschinger J, Petronczki M, Knoblich JA (2004) Sequential roles of Cdc42, Par-6, aPKC, and Lgl in the establishment of epithelial polarity during Drosophila embryogenesis. Dev Cell 6:845-854.

Ivanov DB, Philippova MP, Tkachuk VA (2001) Structure and functions of classical cadherins. Biochemistry (Mosc) 66:1174-1186.

Izumi Y, Ohta N, Hisata K, Raabe T, Matsuzaki F (2006) Drosophila Pinsbinding protein Mud regulates spindle-polarity coupling and centrosome organization. Nat Cell Biol 8:586-593.

Jaegle M, Ghazvini M, Mandemakers W, Piirsoo M, Driegen S, Levavasseur F, Raghoenath S, Grosveld F, Meijer D (2003) The POU proteins Brn-2 and Oct-6 share important functions in Schwann cell development. Genes Dev 17:1380-1391.

Kakunaga S, Ikeda W, Itoh S, Deguchi-Tawarada M, Ohtsuka T, Mizoguchi A, Takai Y (2005) Nectin-like molecule-1/TSLL1/SynCAM3: a neural tissue-specific immunoglobulin-like cell-cell adhesion molecule localizing at non-junctional contact sites of presynaptic nerve terminals, axons and glia cell processes. J Cell Sci 118:1267-1277.

Konno D, Shioi G, Shitamukai A, Mori A, Kiyonari H, Miyata T, Matsuzaki F (2008) Neuroepithelial progenitors undergo LGN-dependent planar divisions to maintain self-renewability during mammalian neurogenesis. Nat Cell Biol 10:93-101.

Le Bivic A (2005) E-cadherin-mediated adhesion is not the founding event of epithelial cell polarity in Drosophila. Trends Cell Biol 15:237-240.

Lom B, Höpker V, McFarlane S, Bixby JL, Holt CE (1998) Fibroblast growth factor receptor signaling in Xenopus retinal axon extension. J Neurobiol 37:633-641.

Maeda M, Johnson KR, Wheelock MJ (2005) Cadherin switching: essential for behavioral but not morphological changes during an epithelium-tomesenchyme transition. J Cell Sci 118:873-887.

Maurel P, Einheber S, Galinska J, Thaker P, Lam I, Rubin MB, Scherer SS, Murakami Y, Gutmann DH, Salzer JL (2007) Nectin-like proteins mediate axon Schwann cell interactions along the internode and are essential for myelination. J Cell Biol 178:861-874

Michailov GV, Sereda MW, Brinkmann BG, Fischer TM, Haug B, Birchmeier C, Role L, Lai C, Schwab MH, Nave KA (2004) Axonal neuregulin-1 regulates myelin sheath thickness. Science 304:700-703.

Morin X, Jaouen F, Durbec P (2007) Control of planar divisions by the 
G-protein regulator LGN maintains progenitors in the chick neuroepithelium. Nat Neurosci 10:1440-1448.

Munro EM (2006) PAR proteins and the cytoskeleton: a marriage of equals. Curr Opin Cell Biol 18:86-94.

Nave KA, Salzer JL (2006) Axonal regulation of myelination by neuregulin 1. Curr Opin Neurobiol 16:492-500.

Ng BK, Chen L, Mandemakers W, Cosgaya JM, Chan JR (2007) Anterograde transport and secretion of endogenous BDNF along sensory axons promotes Schwann cell myelination. J Neurosci 27:7597-7603.

Nodari A, Zambroni D, Quattrini A, Court FA, D’Urso A, Recchia A, Tybulewicz VL, Wrabetz L, Feltri ML (2007) Betal integrin activates Racl in Schwann cells to generate radial lamellae during axonal sorting and myelination. J Cell Biol 177:1063-1075.

Perez-Moreno M, Jamora C, Fuchs E (2003) Sticky business: orchestrating cellular signals at adherens junctions. Cell 112:535-548.

Rose LS, Kemphues KJ (1998) Early patterning of the C. elegans embryo. Annu Rev Genet 32:521-545.

Siller KH, Cabernard C, Doe CQ (2006) The NuMA-related Mud protein binds Pins and regulates spindle orientation in Drosophila neuroblasts. Nat Cell Biol 8:594-600.

Spiegel I, Adamsky K, Eshed Y, Milo R, Sabanay H, Sarig-Nadir O, Horresh I, Scherer SS, Rasband MN, Peles E (2007) A central role for Necl4 (SynCAM4) in Schwann cell-axon interaction and myelination. Nat Neurosci 10:861-869

Takai Y, Irie K, Shimizu K, Sakisaka T, Ikeda W (2003) Nectins and nectinlike molecules: roles in cell adhesion, migration, and polarization. Cancer Sci 94:655-667.
Taveggia C, Zanazzi G, Petrylak A, Yano H, Rosenbluth J, Einheber S, Xu X, Esper RM, Loeb JA, Shrager P, Chao MV, Falls DL, Role L, Salzer JL (2005) Neuregulin-1 type III determines the ensheathment fate of axons. Neuron 47:681-694.

Utton MA, Eickholt B, Howell FV, Wallis J, Doherty P (2001) Soluble $\mathrm{N}$-cadherin stimulates fibroblast growth factor receptor dependent neurite outgrowth and $\mathrm{N}$-cadherin and the fibroblast growth factor receptor co-cluster in cells. J Neurochem 76:1421-1430.

Wanner IB, Wood PM (2002) N-cadherin mediates axon-aligned process growth and cell-cell interaction in rat Schwann cells. J Neurosci 22:4066-4079.

Wanner IB, Guerra NK, Mahoney J, Kumar A, Wood PM, Mirsky R, Jessen KR (2006) Role of N-cadherin in Schwann cell precursors of growing nerves. Glia 54:439-459.

Wei SY, Escudero LM, Yu F, Chang LH, Chen LY, Ho YH, Lin CM, Chou CS, Chia W, Modolell J, Hsu JC (2005) Echinoid is a component of adherens junctions that cooperates with DE-Cadherin to mediate cell adhesion. Dev Cell 8:493-504.

Yamauchi J, Chan JR, Shooter EM (2003) Neurotrophin 3 activation of TrkC induces Schwann cell migration through the c-Jun N-terminal kinase pathway. Proc Natl Acad Sci U S A 100:14421-14426.

Young P, Boussadia O, Berger P, Leone DP, Charnay P, Kemler R, Suter U (2002) E-cadherin is required for the correct formation of autotypic adherens junctions of the outer mesaxon but not for the integrity of myelinated fibers of peripheral nerves. Mol Cell Neurosci 21:341351. 